\title{
An analysis of the variations and clinical applications of the lateral circumflex femoral artery
}

\author{
M. Ma, H. Sang, Y. Ye, H. Zhuang, Z. Zhuang, Y. Qiu, X. Li, D. Xu, M.H. Jiang \\ Department of Human Anatomy Zhongshan School of Medicine, Sun Yat-sen University, Guangzhou, P.R. China
}

[Received: 28 June 2020; Accepted: 8 July 2020; Early publication date: 14 August 2020]

\begin{abstract}
Background: Identifying the arterial variation of the lateral circumflex femoral artery (LCFA) is a vital step in planning surgical and radiological approach. The aim of the study was to evaluate the variations and discuss the clinical correlates of the LCFA.

Materials and methods: Fifty eight adult cadavers (male 45, female 13) with 115 usable sides were used to assess and classify the origin and branches of the LCFA. Also its external diameter, distance from mid-inguinal ligament to sites of origin from the profunda femoris artery or femoral arteries.

Results: There were seven types of LCFA variations in this sample. We classified them as types $A$ to $G$, of which type $A$ was normal, that is, the one showing a single LCFA arising from the profunda femoris artery. Nearly $50.43 \%$ of the sample had type $B-G$ variations, each having $13,10,23,4,4$, and 3 cases, accounting for $11.30 \%, 8.70 \%, 20.00 \%, 3.48 \%, 3.48 \%$, and $2.61 \%$, respectively. Conclusions: There are many variant types in the LCFA. To avoid iatrogenic injuries, clinicians must have a sound understanding of the variation types of this important blood vessel. (Folia Morphol 2021; 80, 3: 557-566)
\end{abstract}

Key words: lateral circumflex femoral artery, variation, anatomy, clinical significance

\section{INTRODUCTION}

The lateral circumflex femoral artery (LCFA) branches from the lateral part of the root of the profunda femoris artery (PFA) and runs horizontally and laterally on the back of the sartorius and rectus femoris muscles. It divides into ascending, transverse, and descending branches [25]. There are several reports of variations of the LCFA and PFA $[8,17,19]$ including many case reports in domestic and international literature. Statistically, there is a dearth of published literature analysing the morphometric, types of variations, and clinical significance of the LCFA. With the continued development of vascularised skin flap and vascularised bone reconstruction transplantations as well as the improvement in radiological diagnosis and treatment of peripheral vascular diseases, PFA and its branches have become of important clinical value [13]. In particular, the LCFA and its branches are of great significance in the vascular transplantation and reconstruction surgery $[1,15,23]$. Therefore, this study was designed to provide detailed anatomical data for clinical use by analysing the variations of the LCFA in a sample of 58 cadavers.

Address for correspondence: M.H. Jiang, MD, PhD, Department of Human Anatomy Zhongshan School of Medicine, Sun Yat-sen University, Guangzhou, P.R. China, tel: (86)-20-87330639, e-mail: jiangmh2@mail.sysu.edu.cn; Dr. D. Xu, Department of Human Anatomy Zhongshan School of Medicine, Sun Yat-sen University, Guangzhou, P.R. China, tel: (86)-20-87330639, e-mail: 462695262@qq.com 


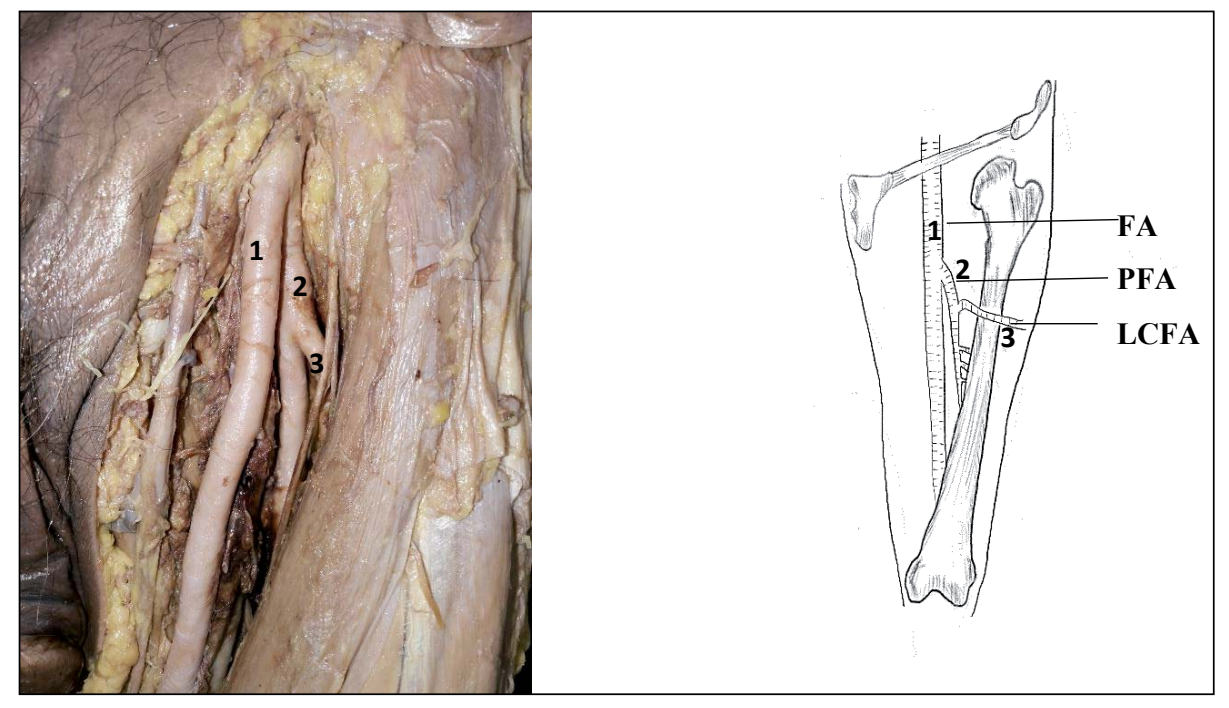

Figure 1. Type A variation in which one single lateral circumflex femoral artery (LCFA) originated from the profunda femoris artery (PFA). A picture: 1 - femoral artery (FA); 2-PFA; 3 - LCFA.

\section{MATERIALS AND METHODS}

\section{Materials}

Fifty-eight (male 45, female 13) formalin-fixed adult cadavers from the Department of Human Anatomy, Sun Yat-sen School of Medicine were used in this study resulting in 115 usable LCFAs. Dissection instruments for routine use in gross anatomy such as scalpels, haemostatic forceps, etc. were used. A calibrated Vernier calliper was used for measurement (accuracy $0.01 \mathrm{~mm}$ ). The specimens were preserved in $10 \%$ neutral formalin fixative solution.

\section{Methods}

The formalin-fixed and undissected cadavers destined to be used in gross anatomy teaching/dissections (i.e. the skin of the lower abdomen and upper thigh did not have any surgical marks or signs of having been dissected) were selected for meticulous exposure of the femoral artery, its profunda branch as well as the LCFA. The origin of femoral artery (FA) and LCFA and their branches were carefully exposed and observed following a pre-established protocol of lower limb femoral region dissection described previously [11]. Verification of the identities, courses, and branches of the FA, PFA, and LCFA, as well as any variations, were done by two senior anatomists (X.D.Z. and J.M.H., corresponding authors). The external diameters of the FA, PFA and LCFA, the distance between the starting point of the PFA and the midpoint of the inguinal ligament, and the distance between the starting point of the LCFA and the starting point of the PFA were measured with a Vernier calliper and string tracing method. The (Z3i, vivo, China) smartphone was used for recording the images of the in situ anatomy and any variations encountered.

\section{RESULTS}

Our team conducted an anatomical study on 115 extremities of 58 cadavers. There were seven types of origin variations of the LCFA, namely type $A$ (one single LCFA originated from the PFA, Fig. 1); type $B$ (one single LCFA originated from the FA, Fig. 2); type $C$ (one single LCFA and PFA that arose from a common stem, Fig. 3); type D (two LCFAs both originated from the PFA, Fig. 4); type E (one LCFA originated from the PFA, while the other originated from the FA, Fig. 5); type $F$ (one LCFA originated from the PFA, the other arose from a common stem with the PFA, Fig. 6); type $G$ (one LCFA originated from the FA, the other arose from a common stem with the PFA, Fig. 7).

Type $A$ was the most prevalent variation (58 out of $115,50.43 \%$ ) while 13 out of the $115(11.30 \%)$ specimens were type $B$. The average distances from the midpoint of the inguinal ligament to the origins of the LCFA and the PFA from the FA were $42.65 \pm$ $\pm 13.87 \mathrm{~mm}$ and $33.15 \pm 16.37 \mathrm{~mm}$, respectively. The average external diameter of the FA was $9.50 \pm 2.53 \mathrm{~mm}$ while that of the PFA and the LCFA were $4.79 \pm 1.26 \mathrm{~mm}$ and $4.37 \pm 1.13 \mathrm{~mm}$, respectively (Tables 1 and 2 ).

Ten out of 115 (8.70\%) femoral region specimens had type $C$ variation of the LCFA origin. The average distance between the midpoint of the inguinal lig- 

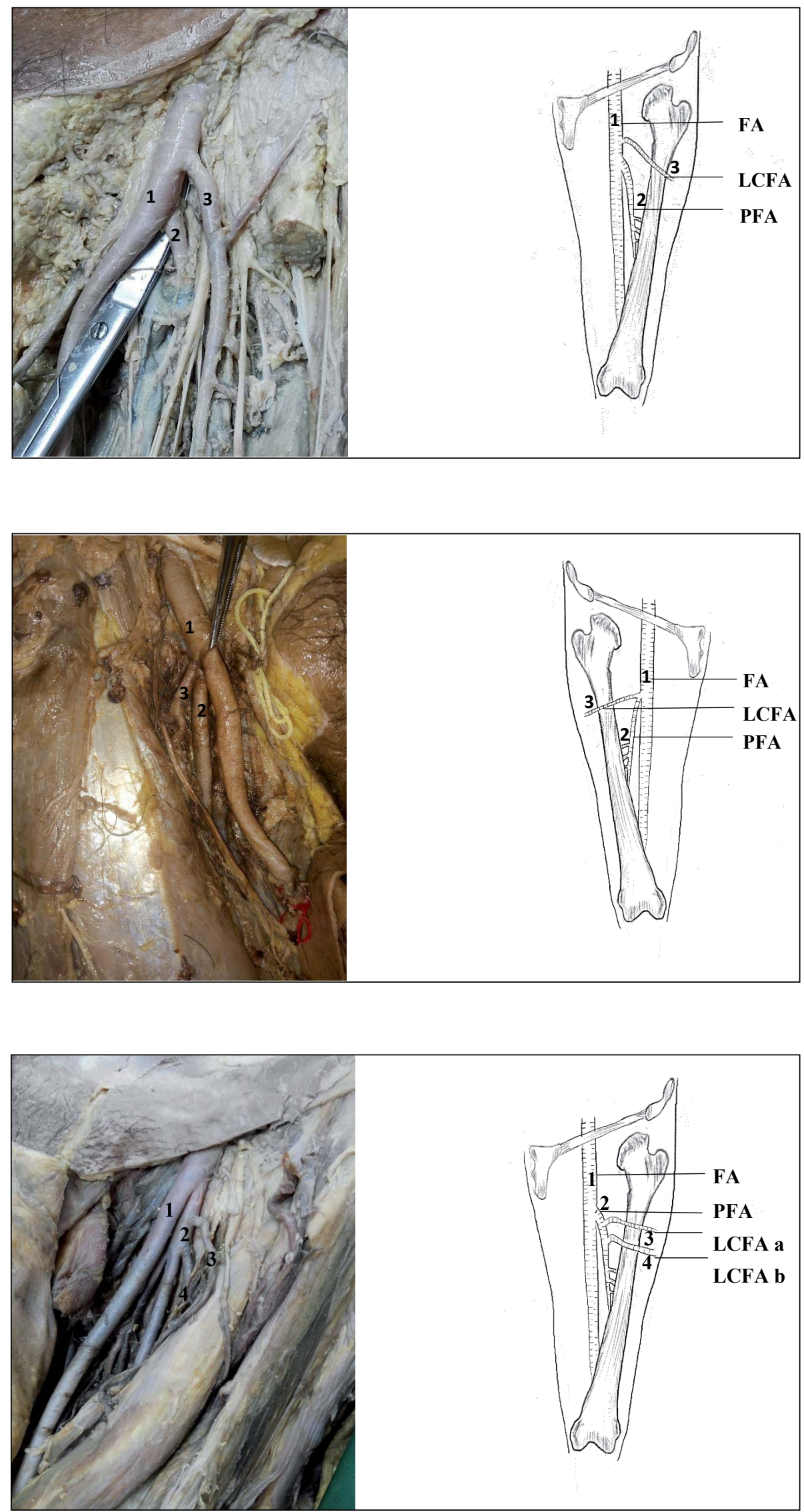

Figure 2. Type $B$ variation in which one single lateral circumflex femoral artery (LCFA) originated from the femoral artery (FA). A picture: $1-\mathrm{FA}$; 2 - profunda femoris artery (PFA); 3 - LCFA.

Figure 3. Type $C$ variation in which one single lateral circumflex femoral artery (LCFA) and profunda femoris artery (PFA) that arose from a common stem. A picture: 1 - femoral artery (FA); 2 - PFA; 3 - LCFA.

Figure 4. Type $D$ variation in which two lateral circumflex femoral arteries (LCFAs) both originated from the profunda femoris artery (PFA). A picture: 1 - femoral artery (FA); 2 PFA; 3 - the proximal LCFA (LCFA-a); 4 - the distal LCFA (LCFA-b). 

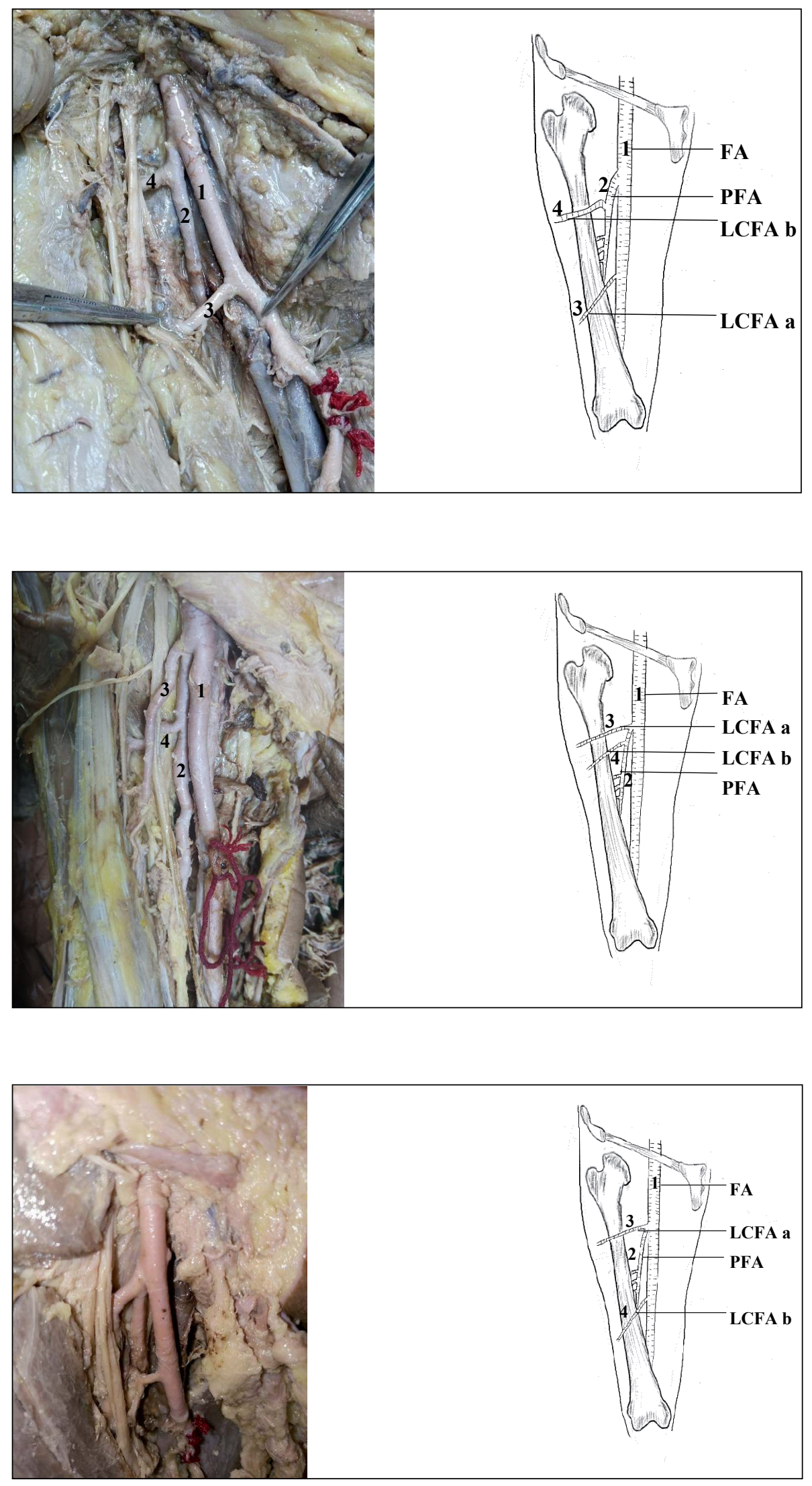

Figure 5. Type Evariation in which one lateral circumflex femoral artery (LCFA) originated from the profunda femoris artery (PFA), while the other originated from the femoral artery (FA). A picture: $1-F A ; 2-P F A$; 3 - LCFA originates from FA (LCFA-a); 4 - LCFA originates from PFA (LCFA-b).

Figure 6. Type $F$ variation in which one lateral circumflex femoral artery (LCFA) originated from the profunda femoris artery (PFA); the other arose from a common stem with the PFA. A picture: 1 - femoral artery (FA); 2 - PFA; 3 - LCFA arises from the common origin with PFA (LCFA-a); 4 - LCFA originates from PFA (LCFA-b).

Figure 7. Type $\mathrm{G}$ variation in which one lateral circumflex femoral artery (LCFA) originated from the femoral artery (FA); the other arose from a common stem with the profunda femoris artery (PFA). A picture: $1-\mathrm{FA}$; 2-PFA; 3 - LCFA arises from a common origin with PFA (LCFA-a); 4 - LCFA originates from FA (LCFA-b). 
ament and the common origin of the PFA and the LCFA from the FA was $34.23 \pm 9.96 \mathrm{~mm}$. The average external diameter of the $F A$ was $9.50 \pm 2.53 \mathrm{~mm}$ while that of the PFA and the LCFA were $4.79 \pm 1.26 \mathrm{~mm}$ and $4.37 \pm 1.13 \mathrm{~mm}$, respectively (Tables 3 and 4 ).

Twenty-three out of $115(20.00 \%)$ specimens bearing the origin of the LCFA were of type D. In this type, the proximal LCFA was defined as LCFA-a, while the distal one defined as LCFA-b. The average distances from the inguinal ligament midpoint to the origin of the LCFA- $a$ and the LCFA-b from the PFA were $17.26 \pm$ $\pm 13.26 \mathrm{~mm}$ and $30.22 \pm 13.84 \mathrm{~mm}$, respectively. The average distance from the midpoint of the inguinal ligament to the exit point of the PFA from the FA was $42.51 \pm 14.55 \mathrm{~mm}$. The average external diameters were as follows: the FA was $8.44 \pm 2.41 \mathrm{~mm}$, that of the PFA

Table 1. Summary of the origin and branches of lateral circumflex femoral artery for type $B$

\begin{tabular}{lcccc}
\hline Item & $\begin{array}{c}\mathbf{N} \\
\text { (branch) }\end{array}$ & $\begin{array}{c}\overline{\mathbf{x}} \pm \mathbf{s} \\
{[\mathbf{m m}]}\end{array}$ & $\begin{array}{c}\text { Minimum } \\
{[\mathbf{m m}]}\end{array}$ & $\begin{array}{c}\text { Maximum } \\
{[\mathbf{m m}]}\end{array}$ \\
\hline PFA-MIL & 13 & $42.65 \pm 13.87$ & 16.23 & 60.64 \\
EDFA & 13 & $9.50 \pm 2.53$ & 5.21 & 13.23 \\
EDPFA & 13 & $4.79 \pm 1.26$ & 2.93 & 6.68 \\
LCFA-MIL & 13 & $33.15 \pm 16.37$ & 6.64 & 66.38 \\
EDLCFA & 13 & $4.37 \pm 1.13$ & 2.40 & 5.52 \\
\hline
\end{tabular}

PFA-MIL — the distance from the midpoint of the inguinal ligament to the origin of the profunda femoris artery; EDFA - the external diameter of the femoral artery; EDPFA - the external diameter of the profunda femoris artery; LCFA-MIL — the distance from the midpoint of the inguinal ligament to the origin of the lateral circumflex femoral artery; EDLCFA - the external diameter of the lateral circumflex femoral artery was $5.91 \pm 1.89 \mathrm{~mm}$, the LCFA-a was $3.77 \pm 1.10 \mathrm{~mm}$ and the LCFA-b was $3.17 \pm 1.16 \mathrm{~mm}$ (Tables 5 and 6 ).

Four out of $115(3.48 \%)$ specimens were variation type $E$. In this type, the LCFA that originatced from the FA was designated LCFA-a, while the one coming from the PFA was designated LCFA-b. The average distances from the midpoint of the inguinal ligament to the origins of the PFA and the LCFA-a from the FA were $46.84 \pm 4.09 \mathrm{~mm}$ and $47.25 \pm 26.48 \mathrm{~mm}$, respectively. The LCFA-b sprung from the PFA about $18.55 \pm 7.03 \mathrm{~mm}$ from where the PFA exited the FA. The average external diameters of the arteries were as follows: the FA $9.14 \pm 2.65 \mathrm{~mm}$, the PFA was $5.54 \pm 1.36 \mathrm{~mm}$, LCFA-a $3.16 \pm 1.28 \mathrm{~mm}$, and the LCFA-b was $4.23 \pm 1.28 \mathrm{~mm}$ wide (Tables 7 and 8 ).

The type $\mathrm{F}$ variations were also encountered in 4 of the $115(3.48 \%)$ specimens. In this variation type, the LCFA and the PFA shared a common origin defined as LCFA-a, while the other one independently arose from the PFA and was named the LCFA-b. The mean length of the LCFA-a from the midpoint of the inguinal ligament to its FA origin was $49.64 \pm 12.40 \mathrm{~mm}$. The LCFA-b exited the PFA about $25.26 \pm 6.64 \mathrm{~mm}$ down the course of the PFA. The average external diameters of the arteries as follows: FA $10.24 \pm 0.78 \mathrm{~mm}$, PFA $6.20 \pm 0.77 \mathrm{~mm}$, LCFA-a $4.48 \pm 1.91$, and LCFA b $3.04 \pm 1.43 \mathrm{~mm}$ (Tables 9 and 10 ).

Only $3(2.61 \%)$ out of 115 specimens were type G variations. In this type, the LCFA arising from a common origin with PFA was defined as LCFA-a, while the one arising directly from the FA named LCFA-b. The average distance from the midpoint of the in-

Table 2. Details of the origin and branches of lateral circumflex femoral artery for type $B$

\begin{tabular}{lllccccc}
\hline Gender & Age & Side (left or right) & PFA-MIL [mm] & EDFA [mm] & EDPFA [mm] & LCFA-MIL [mm] & EDLCFA [mm] \\
\hline Male & Old & Right & 53.21 & 6.84 & 3.73 & 52.09 & 3.82 \\
Male & Old & Right & 52.76 & 10.63 & 6.18 & 21.32 & 5.37 \\
Male & Old & Right & 31.57 & 5.30 & 3.06 & 9.95 & 2.40 \\
Male & Old & Left & 56.28 & 9.17 & 4.70 & 24.66 & 3.61 \\
Male & Old & Right & 19.88 & 8.97 & 5.40 & 66.38 & 5.46 \\
Male & Old & Right & 54.98 & 12.71 & 6.10 & 33.02 & 5.14 \\
Male & Old & Right & 60.64 & 12.20 & 4.23 & 28.32 & 5.02 \\
Male & Old & Left & 54.09 & 11.91 & 5.84 & 42.78 & 5.03 \\
& & Right & 41.43 & 13.23 & 6.68 & 34.96 & 4.96 \\
Female & Old & Left & 44.87 & 9.90 & 5.99 & 6.64 & 5.16 \\
Female & Old & Left & 29.58 & 8.63 & 4.08 & 52.83 & 5.52 \\
Female & Old & Right & 16.23 & 8.79 & 2.93 & 25.26 & 2.78 \\
Female & Old & Right & 38.89 & 5.21 & 3.30 & 32.69 & 2.53 \\
\hline
\end{tabular}

PFA-MIL — the distance from the midpoint of the inguinal ligament to the origin of the profunda femoris artery; EDFA — the external diameter of the femoral artery; EDPFA — the external diameter of the profunda femoris artery; LCFA-MIL — the distance from the midpoint of the inguinal ligament to the origin of the lateral circumflex femoral; EDLCFA — the external diameter of the lateral circumflex femoral artery 
Table 3. Summary of the origin and branches of lateral circumflex femoral artery for type C

\begin{tabular}{lcccc}
\hline Item & $\begin{array}{c}\mathbf{N} \\
\text { (branch) }\end{array}$ & $\begin{array}{c}\overline{\mathbf{x}} \pm \mathbf{s} \\
{[\mathrm{mm}]}\end{array}$ & $\begin{array}{c}\text { Minimum } \\
{[\mathbf{m m}]}\end{array}$ & $\begin{array}{c}\text { Maximum } \\
{[\mathbf{m m}]}\end{array}$ \\
\hline CPFALCFA-MIL & 10 & $34.23 \pm 9.96$ & 24.22 & 56.73 \\
EDFA & 10 & $9.37 \pm 2.27$ & 5.51 & 13.4 \\
EDPFA & 10 & $5.50 \pm 1.88$ & 3.05 & 8.92 \\
EDLCFA & 10 & $4.51 \pm 1.47$ & 2.07 & 7.41 \\
\hline
\end{tabular}

CPFALCFA-MIL — the distance from the common origin of the profunda artery and lateral circumflex femoral artery to the midpoint of the inguinal ligament; EDFA — the external diameter of the femoral artery; EDPFA - the external diameter of the profunda femoris artery; EDLCFA - the external diameter of the lateral circumflex femoral artery

guinal ligament to the common origin of the PFA and the LCFA-a from the FA was $92.92 \pm 4.40 \mathrm{~mm}$. The average distance from the midpoint of the inguinal ligament to the origin of LCFA-b on the FA was $45.72 \pm 6.18 \mathrm{~mm}$. The average external diameters of the arteries were as follows: FA $9.85 \pm 0.73 \mathrm{~mm}$, PFA $6.04 \pm 0.54 \mathrm{~mm}$, LCFA-a $3.61 \pm 1.11$, and LCFA-b $5.11 \pm 0.76 \mathrm{~mm}$ (Tables 11 and 12).

\section{DISCUSSION}

The profunda artery and the lateral circumflex femoral artery are prone to having many types of variations. Previously, Shi et al. described the variations of the LCFA and, divided them into four categories namely those originating from the profunda femoris artery and those from the femoral artery as well as the number of roots of origin [21] accounting for $25.00 \%$ and $76.56 \% ; 90.62 \%$ and $9.38 \%$, respectively. If classified according to this method, the four types of data measured by the author account for $15.15 \%$ and $84.84 \% ; 70.43 \%$, and $29.57 \%$, respectively. The frequency with which the LCFA emanated from the
Table 5. Summary of the origin and branches of lateral circumflex femoral artery for type $D$

\begin{tabular}{lcccc}
\hline Item & $\begin{array}{c}\mathbf{N} \\
\text { (branch) }\end{array}$ & $\begin{array}{c}\overline{\mathbf{x}} \pm \mathbf{s} \\
{[\mathrm{mm}]}\end{array}$ & $\begin{array}{c}\text { Minimum } \\
{[\mathrm{mm}]}\end{array}$ & $\begin{array}{c}\text { Maximum } \\
{[\mathrm{mm}]}\end{array}$ \\
\hline PFA-MIL & 23 & $42.51 \pm 14.55$ & 24.18 & 82.25 \\
EDFA & 23 & $8.44 \pm 2.41$ & 4.13 & 13.33 \\
EDPFA & 23 & $5.91 \pm 1.89$ & 3.09 & 10.17 \\
LCFA a-PFA & 23 & $17.26 \pm 13.26$ & 4.32 & 59.55 \\
LCFA b-PFA & 23 & $30.22 \pm 13.84$ & 11.14 & 59.55 \\
EDLCFA a & 23 & $3.77 \pm 1.10$ & 2.23 & 6.56 \\
EDLCFA b & 23 & $3.17 \pm 1.16$ & 1.35 & 5.95 \\
\hline
\end{tabular}

PFA-MIL - the distance from the origin of the profunda femoris artery to the midpoint of the inguinal ligament; EDFA — the external diameter of the femoral artery; EDPFA the external diameter of the profunda femoris artery; LCFA a-PFA - the distance from the origin of the LCFA a to the origin of the profunda femoris artery; LCFA b-PFA - the distance from the origin of the LCFA $b$ to the origin of the profunda femoris artery; EDLCFA $a$ the external diameter of the LCFA $a$; EDLCFA $b$ - the external diameter of the LCFA $b$

profunda femoris artery was higher than that from the femoral artery, and the number of cases with a single circumflex femoral artery was also more than those with a double. These findings were consistent with the results of Shi et al. [21]. The majority of the LCFAs originated from the profunda femoris artery while a fewer were from the femoral artery or the common stem with the profunda femoris artery [22]. Daksha Dixit et al. [3] studied 114 cases (228 specimens) and found that the LCFA originated from the profunda femoris artery in 171 (75\%) specimens, from the femoral artery in $18(7.89 \%)$ specimens and also from a common stem in $31(13.59 \%)$ specimens. Labetowicz et al. [11] found that the LCFA arises from the profunda femoris artery or the femoral artery in $78.75 \%$ and $21.25 \%$ of cases, respectively. Also, Tomaszewski et al. [26] reported that the lat-

Table 4. Details of the origin and branches of lateral circumflex femoral artery for type $C$

\begin{tabular}{lllcccc}
\hline Gender & Age & Orientation & CPFALCFA-MI [mm] & EDFA [mm] & EDPFA [mm] & EDLCFA [mm] \\
\hline Male & Old & Right & 34.82 & 10.09 & 5.90 & 5.61 \\
Male & Old & Right & 29.44 & 10.70 & 6.88 & 4.77 \\
Male & Young & Left & 42.55 & 5.51 & 3.89 & 2.07 \\
Male & Old & Left & 56.73 & 11.57 & 5.07 & 4.66 \\
Male & Old & Left & 24.43 & 10.64 & 8.16 & 7.41 \\
Male & Old & Right & 43.42 & 13.40 & 8.92 & 5.81 \\
Female & Old & Left & 32.83 & 8.82 & 4.93 & 4.40 \\
& & Right & 28.28 & 8.18 & 4.98 & 3.65 \\
Female & Old & Right & 24.22 & 7.10 & 3.21 & 3.98 \\
Female & Old & Left & 25.55 & 7.69 & 3.05 & 2.72 \\
\hline
\end{tabular}

CPFALCFA-MIL — the distance from the common origin of the profunda artery and lateral circumflex femoral artery to the midpoint of the inguinal ligament; EDFA — the external diameter of the femoral artery; EDPFA - the external diameter of the profunda femoris artery; EDLCFA - the external diameter of the lateral circumflex femoral artery 
Table 6. Details of the origin and branches of lateral circumflex femoral artery for type $D$

\begin{tabular}{|c|c|c|c|c|c|c|c|c|c|}
\hline Gender & Age & Orientation & $\begin{array}{c}\text { PFA-MIL } \\
{[\mathrm{mm}]}\end{array}$ & $\begin{array}{l}\text { EDFA } \\
{[\mathrm{mm}]}\end{array}$ & $\begin{array}{c}\text { EDPFA } \\
{[\mathrm{mm}]}\end{array}$ & $\begin{array}{c}\text { LCFA a-PFA } \\
{[\mathrm{mm}]}\end{array}$ & $\begin{array}{c}\text { LCFA b-PFA } \\
{[\mathrm{mm}]}\end{array}$ & $\begin{array}{c}\text { EDLCFA a } \\
{[\mathrm{mm}]}\end{array}$ & $\begin{array}{c}\text { EDLCFA b } \\
{[\mathrm{mm}]}\end{array}$ \\
\hline \multirow[t]{2}{*}{ Male } & Old & Left & 32.69 & 8.85 & 5.04 & 19.18 & 25.58 & 2.80 & 2.29 \\
\hline & & Right & 82.25 & 8.65 & 4.45 & 4.32 & 20.42 & 2.35 & 2.78 \\
\hline Male & Old & Left & 33.31 & 8.98 & 6.20 & 40.54 & 58.69 & 2.79 & 2.35 \\
\hline Male & Old & Left & 24.18 & 7.74 & 5.42 & 5.83 & 23.26 & 2.69 & 2.93 \\
\hline \multirow[t]{2}{*}{ Male } & Young & Left & 28.78 & 4.13 & 4.11 & 7.70 & 19.39 & 3.89 & 3.16 \\
\hline & & Right & 26.27 & 5.83 & 5.39 & 5.64 & 15.97 & 4.10 & 3.83 \\
\hline Male & Old & Right & 47.41 & 10.23 & 8.61 & 15.96 & 20.55 & 4.87 & 5.08 \\
\hline Male & Old & Right & 43.44 & 5.23 & 3.68 & 6.93 & 13.29 & 3.23 & 2.60 \\
\hline Male & Young & Right & 39.65 & 4.44 & 3.09 & 8.76 & 31.74 & 3.15 & 2.26 \\
\hline \multirow[t]{2}{*}{ Male } & Old & Left & 48.01 & 10.02 & 7.88 & 14.91 & 32.85 & 6.56 & 1.35 \\
\hline & & Right & 37.02 & 9.60 & 7.21 & 18.97 & 35.22 & 5.76 & 5.95 \\
\hline \multirow[t]{2}{*}{ Male } & Old & Left & 36.91 & 9.65 & 7.03 & 4.63 & 23.63 & 4.52 & 2.50 \\
\hline & & Right & 27.10 & 9.50 & 7.07 & 29.19 & 53.74 & 3.69 & 1.55 \\
\hline Male & Old & Left & 52.47 & 4.90 & 3.50 & 27.38 & 42.14 & 3.46 & 2.53 \\
\hline Male & Middle & Right & 46.91 & 6.95 & 3.99 & 13.63 & 11.14 & 3.12 & 2.20 \\
\hline Male & Old & Left & 47.55 & 11.05 & 7.90 & 22.45 & 23.98 & 3.38 & 4.36 \\
\hline Male & Old & Right & 47.23 & 10.20 & 5.53 & 59.55 & 59.55 & 2.23 & 3.06 \\
\hline Male & Old & Right & 36.70 & 9.56 & 6.88 & 11.37 & 40.18 & 3.19 & 3.99 \\
\hline Male & Old & Right & 29.19 & 9.69 & 4.94 & 9.78 & 29.28 & 4.04 & 3.07 \\
\hline Male & Old & Left & 42.26 & 10.14 & 8.89 & 18.62 & 18.62 & 5.62 & 4.78 \\
\hline Male & Old & Right & 38.21 & 13.33 & 10.17 & 34.56 & 47.82 & 4.68 & 4.56 \\
\hline Female & Old & Right & 80.50 & 10.67 & 5.12 & 10.37 & 29.90 & 3.04 & 1.89 \\
\hline Female & Old & Left & 39.86 & 4.90 & 3.94 & 6.70 & 18.15 & 3.50 & 3.87 \\
\hline
\end{tabular}

PFA-MIL — the distance from the origin of the profunda femoris artery to the midpoint of the inguinal ligament; EDFA - the external diameter of the femoral artery; EDPFA - the external diameter of the profunda femoris artery; LCFA a-PFA - the distance from the origin of the LCFA a to the origin of the profunda femoris artery; LCFA b-PFA - the distance from the origin of the LCFA $b$ to the origin of the profunda femoris artery; EDLCFA $a$ - the external diameter of the LCFA $a$; EDLCFA $b$ - the external diameter of the LCFA $b$

eral circumflex artery was a branch of the profunda femoris artery and the femoral artery in $76.1 \%$ and $19.6 \%$, respectively. Liu et al. [13] divided branches of the profunda artery into four types based on clinical application. In the present sample of 115 cases, the lateral circumflex femoral arteries were classified according to their origin and number of roots giving rise to seven types (six of which were variations). The prevalence of the variations, named herein type $A$ to $G$, was $50.43 \%, 11.30 \%, 8.70 \%, 20.00 \%, 3.48 \%$, 3.48\%, and $2.61 \%$, respectively.

Based on the variation type, the distance from the mid-point of the inguinal ligament to the origin of the profunda femoris artery was $40.41 \pm 13.72 \mathrm{~mm}$ (minimum $13.73 \mathrm{~mm}$, maximum $83.64 \mathrm{~mm}$ ). Nasr et al. found that the mean distance between the midpoint of the inguinal ligament and the origin of PFA and was $51.5 \pm 1.9 \mathrm{~mm}$ on the right side and $49.7 \pm$ $\pm 1.9 \mathrm{~mm}$ on the left side in males, and $48.5 \pm 2.2 \mathrm{~mm}$ on the right side and $48.9 \pm 2.2 \mathrm{~mm}$ on the left side in females [16]. This difference in morphometric data could be the result of individual and racial differences in anthropometric characteristics. Interventions involving cannulation of the femoral artery are being widely used in clinical practice [3]. During the process of puncturing the femoral artery and inserting a cannula, the profunda femoris artery should be avoided as much as possible to prevent the guidewire and catheter straying into it. If the profunda femoris artery is abnormally placed or the origin too high, the guidewire and catheter might easily stray into it [6]. This study provides anatomical data that can help access the femoral artery during clinical intubation, and doctors should pay attention to the unique situation of each patient during femoral artery puncture.

According to the variation type, the diameter of the lateral circumflex femoral artery was $4.30 \pm 1.43 \mathrm{~mm}$ (minimum $1.01 \mathrm{~mm}$, maximum $7.91 \mathrm{~mm}$ ) and the average point of origin of the LCFA was $56.98 \mathrm{~mm}$ below the inguinal ligament. The deep branch (ascend- 
Table 7. Summary of the origin and branches of lateral circumflex femoral artery for type $\mathrm{E}$

\begin{tabular}{lcccc}
\hline Item & $\begin{array}{c}\mathbf{N} \\
\text { (branch) }\end{array}$ & $\begin{array}{c}\overline{\mathbf{x}} \pm \mathbf{s} \\
{[\mathrm{mm}]}\end{array}$ & $\begin{array}{c}\text { Minimum } \\
{[\mathrm{mm}]}\end{array}$ & $\begin{array}{c}\text { Maximum } \\
{[\mathrm{mm}]}\end{array}$ \\
\hline PFA-MIL & 4 & $46.84 \pm 4.09$ & 42.32 & 51.44 \\
EDFA & 4 & $9.14 \pm 2.65$ & 5.29 & 11.81 \\
EDPFA & 4 & $5.54 \pm 1.36$ & 3.97 & 7.71 \\
LCFA a-MIL & 4 & $47.25 \pm 26.48$ & 18.69 & 78.49 \\
LCFA b-PFA & 4 & $18.55 \pm 7.03$ & 8.59 & 27.88 \\
EDLCFA a & 4 & $3.16 \pm 1.28$ & 1.01 & 4.26 \\
EDLCFA b & 4 & $4.23 \pm 1.28$ & 2.80 & 6.00 \\
\hline
\end{tabular}

PFA-MIL — the distance from the origin of the profunda femoris artery to the midpoint of the inguinal ligament; EDFA - the external diameter of the femoral artery; EDPFA the external diameter of the profunda femoris artery; LCFA a-MIL — the distance from the origin of the LCFA a to the midpoint of the inguinal ligament; LCFA b-PFA - the distance from the origin of the LCFA $b$ to the origin of the profunda femoris artery; EDLCFA $a$ - the

external diameter of the LCFA a; EDLCFA $b$ - the external diameter of the LCFA $b$
Table 9. Summary of the origin and branches of lateral circumflex femoral artery for type $F$

\begin{tabular}{lcccc}
\hline Item & $\begin{array}{c}\mathbf{N} \\
\text { (branch) }\end{array}$ & $\begin{array}{c}\overline{\mathbf{x}} \pm \mathbf{s} \\
{[\mathrm{mm}]}\end{array}$ & $\begin{array}{c}\text { Minimum } \\
{[\mathrm{mm}]}\end{array}$ & $\begin{array}{c}\text { Maximum } \\
{[\mathrm{mm}]}\end{array}$ \\
\hline CPFALCFA a-MIL & 4 & $49.64 \pm 12.40$ & 37.88 & 68.55 \\
EDFA & 4 & $10.24 \pm 0.78$ & 9.52 & 11.56 \\
EDPFA & 4 & $6.20 \pm 0.77$ & 4.88 & 6.79 \\
LCFA b- PFA & 4 & $25.26 \pm 6.64$ & 17.24 & 35.70 \\
EDLCFA a & 4 & $4.48 \pm 1.91$ & 3.25 & 7.79 \\
EDLCFA b & 4 & $3.04 \pm 1.43$ & 1.31 & 4.98
\end{tabular}

CPFALCFA a-MIL — the distance from the common origin of the profunda artery and LCFA a to the midpoint of the inguinal ligament; EDFA - the external diameter of the femoral artery; EDPFA - the external diameter of the profunda femoris artery; LCFA $b$-PFA - the distance from the origin of the LCFA $b$ to the origin of the profunda femoris artery; EDLCFA $a$ - the external diameter of the LCFA a; EDLCFA $b$ - the external diameter of the LCFA $b$

Table 8. Details of the origin and branches of lateral circumflex femoral artery for type $E$

\begin{tabular}{llllcccccc}
\hline Gender & Age & Orientation & $\begin{array}{c}\text { PFA-MIL } \\
{[\mathrm{mm}]}\end{array}$ & $\begin{array}{c}\text { EDFA } \\
{[\mathrm{mm}]}\end{array}$ & $\begin{array}{c}\text { EDPFA } \\
{[\mathrm{mm}]}\end{array}$ & $\begin{array}{c}\text { LCFA a-MIL } \\
{[\mathrm{mm}]}\end{array}$ & $\begin{array}{c}\text { LCFA b-PFA } \\
{[\mathrm{mm}]}\end{array}$ & $\begin{array}{c}\text { EDLCFA a } \\
{[\mathrm{mm}]}\end{array}$ & $\begin{array}{c}\text { EDLCFA b } \\
{[\mathrm{mm}]}\end{array}$ \\
\hline Male & Old & Right & 43.24 & 11.39 & 5.17 & 68.38 & 21.21 & 4.26 & 6.00 \\
Male & Old & Right & 50.37 & 8.08 & 5.31 & 18.69 & 8.59 & 3.92 & 2.80 \\
Male & Old & Right & 51.44 & 11.81 & 7.71 & 23.43 & 27.88 & 3.47 & 3.26 \\
Male & Middle & Left & 42.32 & 5.29 & 3.97 & 78.49 & 16.51 & 1.01 & 4.86 \\
\hline
\end{tabular}

PFA-MIL — the distance from the origin of the profunda femoris artery to the midpoint of the inguinal ligament; EDFA — the external diameter of the femoral artery; EDPFA — the external diameter of the profunda femoris artery; LCFA a-MIL — the distance from the origin of the LCFA a to the midpoint of the inguinal ligament; LCFA b-PFA — the distance from the origin of the LCFA $b$ to the origin of the profunda femoris artery; EDLCFA $a$ - the external diameter of the LCFA $a$; EDLCFA $b$ - the external diameter of the LCFA $b$

Table 10. Details of the origin and branches of lateral circumflex femoral artery (LCFA) for type $F$

\begin{tabular}{lllcccccc}
\hline Gender & Age & Orientation & $\begin{array}{c}\text { CPFALCFA a-MIL } \\
{[\mathrm{mm}]}\end{array}$ & $\begin{array}{c}\text { EDFA } \\
{[\mathrm{mm}]}\end{array}$ & $\begin{array}{c}\text { EDPFA } \\
{[\mathrm{mm}]}\end{array}$ & $\begin{array}{c}\text { LCFA b-PFA } \\
{[\mathrm{mm}]}\end{array}$ & $\begin{array}{c}\text { EDLCFA a } \\
{[\mathrm{mm}]}\end{array}$ & $\begin{array}{c}\text { EDLCFA b } \\
{[\mathrm{mm}]}\end{array}$ \\
\hline Male & Old & Left & 52.89 & 11.56 & 6.60 & 23.58 & 3.60 & 2.08 \\
Male & Old & Right & 37.88 & 9.52 & 4.88 & 35.70 & 7.79 & 1.31 \\
Male & Old & Left & 68.55 & 10.01 & 6.52 & 17.24 & 3.29 & 4.98 \\
Male & Old & Right & 39.22 & 9.85 & 6.79 & 24.53 & 3.25 & 3.77 \\
\hline
\end{tabular}

CPFALCFA a-MIL — the distance from the common origin of the profunda artery and LCFA a to the midpoint of the inguinal ligament; EDFA — the external diameter of the femoral artery; EDPFA - the external diameter of the profunda femoris artery; LCFA $b$-PFA - the distance from the origin of the LCFA $b$ to the origin of the profunda femoris artery; EDLCFA a the external diameter of the LCFA a; EDLCFA $b$ - the external diameter of the LCFA $b$

ing branch) of the LCFA nourishes the femoral head and neck, and the diameter and position of the vessel should allow for catheter insertion. This feat can easy and safe to treat avascular necrosis of the femoral head [4]. Therefore, data contained in this article provide an anatomical basis for safe endovascular interventions in the treatment of avascular necrosis of the femoral head via the ascending branch of the LCFA.

The applied anatomy of the LCFA, an important branch of the profunda femoris artery, is of great significance in the clinical practice. For instance, it is responsible for vascularisation of the greater trochanter, head, and neck of the femur as well as the vastus lateralis muscle and the knee complex [26]. The lateral circumflex femoral artery is closely associated with the soft tissues around the hip joint and the head and neck of the femur, putting it at risk during traumatic damage to the hip joint and femoral neck $[5,10]$. Knowledge of the anatomical variations of the profunda femoris artery and its circumflex branches is vital in angiographic diagnostic procedures and during surgical or radiological interventions involv- 
Table 11. Summary of the origin and branches of lateral circumflex femoral artery for type $G$

\begin{tabular}{lcccc}
\hline Item & $\begin{array}{c}\mathbf{N} \\
\text { (branch) }\end{array}$ & $\begin{array}{c}\overline{\mathbf{x}} \pm \mathbf{s} \\
{[\mathbf{m m}]}\end{array}$ & $\begin{array}{c}\text { Minimum } \\
{[\mathbf{m m}]}\end{array}$ & $\begin{array}{c}\text { Maximum } \\
{[\mathbf{m m}]}\end{array}$ \\
\hline CPFALCFA a-MIL & 3 & $92.92 \pm 4.40$ & 86.71 & 96.19 \\
EDFA & 3 & $9.85 \pm 0.73$ & 9.12 & 10.85 \\
EDPFA & 3 & $6.04 \pm 0.54$ & 5.55 & 6.79 \\
LCFA b-MIL & 3 & $45.72 \pm 6.18$ & 40.92 & 54.44 \\
EDLCFA a & 3 & $3.64 \pm 1.11$ & 2.23 & 4.94 \\
EDLCFA b & 3 & $5.11 \pm 0.76$ & 4.04 & 5.65
\end{tabular}

CPFALCFA a-MIL - the distance from the common origin of the profunda artery and LCFA a to the midpoint of the inguinal ligament; EDFA — the external diameter of the femoral artery; EDPFA — the external diameter of the profunda femoris artery; LCFA b-MIL - the distance from the origin of the LCFA $b$ to the midpoint of the inguinal ligament; EDLCFA $a$ - the external diameter of the LCFA a; EDLCFA $b$ - the external diameter of the LCFA $b$

ing the femoral region. Orthopaedic surgeons and interventional radiologists must be aware of potential variations of the site of origin and course of the lateral circumflex femoral artery when performing clinical operations such as femoral triangle surgery and hip joint replacement, and vascular radiological intervention such as arterial catheterisation and arteriography $[18,27]$, as a means to avoid iatrogenic injury and decrease the risks of intra-operative posthaermorrhage, as well as post-operative complications. For instance, the popular anterior approach of hip surgery routinely requires the ligation of the ascending branch of the LCFA. It may jeopardize vascularisation of the proximal femur, especially in conditions of anatomical variations [7].

It is also widely used and of surgical value in thigh flaps [14]. The thigh flap supplied by LCFA and its branches has a great clinical significance in flap plastic surgery, including repairing large soft tissue defect of the extremities [9], head-and-neck region [20] and knee [2], as well as reconstructing defects resulted from perineal and hypogastric tumour resection [24]. For example, the retrograde anterolateral femoral flap with a descending lateral branch of the femoral circumflex artery and the perforating branch of the lateral superior genu artery can better repair soft tissue defects around the knee and middle and upper leg, with sufficient blood supply and satisfactory outcomes [28]. Nevertheless, the anatomical variability of the LCFA complicate the harvest of thigh flaps, thus adequate awareness of these anatomical properties will be conducive to flap refinements and donor-site management [12].

The expanding scope of vascular transplantation and reconstruction has prompted this study on the variations of LCFA and its branches. In patients with iliofemoral artery thrombosis, the LCFA can provide an alternative outflow route for the main artery bypass [23]. Besides, it can be utilized as a high-flow conduit in extracranial-intracranial (EC-IC) bypass surgery in patients with intracranial disease requiring sacrifice of the parent vessel, for example, aneurysm [1]. In recent era, the descending branch of the LCFA has gained popularity in coronary artery bypass grafting. It is worth noting that related clinical trial group encountered an $18 \%$ to $20 \%$ abandonment rate secondary to anatomical factors [15].

In order to prevent iatrogenic injury and minimise complications, it is of vital importance for radiologists and surgeons to take the variations of LCFA into account during operations in the femoral region and diagnostic interventional procedures, as well as in the field of vascular, plastic and reconstructive surgery. Therefore, a careful examination of blood vessels should be emphasized prior to performing any invasive procedure in femoral region.

\section{CONCLUSIONS}

The data of this study provided anatomical variations of the LCFA and recommend that doctors should have a sound understanding of its variations along with those of the profunda artery. This important to prevent iatrogenic injuries and improve clinical outcomes.

Conflict of interest: None declared

Table 12. Details of the origin and branches of lateral circumflex femoral artery for type $G$

\begin{tabular}{lllcccccc}
\hline Gender & Age & Orientation & $\begin{array}{c}\text { CPFALCFA a-MIL } \\
{[\mathrm{mm}]}\end{array}$ & EDFA [mm] & EDPFA [mm] & $\begin{array}{c}\text { LCFA b-MIL } \\
{[\mathrm{mm}]}\end{array}$ & $\begin{array}{c}\text { EDLCFA a } \\
{[\mathrm{mm}]}\end{array}$ & $\begin{array}{c}\text { EDLCFA b } \\
{[\mathrm{mm}]}\end{array}$ \\
\hline Male & Old & Left & 86.71 & 9.57 & 6.79 & 40.92 & 3.75 & 5.65 \\
Male & Old & Right & 95.87 & 10.85 & 5.77 & 41.80 & 4.94 & 5.64 \\
Male & Old & Left & 96.19 & 9.12 & 5.55 & 54.44 & 2.23 & 4.04 \\
\hline
\end{tabular}

CPFALCFA a-MIL — the distance from the common origin of the profunda artery and LCFA a to the midpoint of the inguinal ligament; EDFA — the external diameter of the femoral artery; EDPFA - the external diameter of the profunda femoris artery; LCFA b-MIL — the distance from the origin of the LCFA $b$ to the midpoint of the inguinal ligament; EDLCFA a - the external diameter of the LCFA a; EDLCFA $b$ - the external diameter of the LCFA $b$ 


\section{REFERENCES}

1. Başkaya MK, Kiehn MW, Ahmed AS, et al. Alternative vascular graft for extracranial-intracranial bypass surgery: descending branch of the lateral circumflex femoral artery. Neurosurg Focus. 2008; 24(2): E8, doi: 10.3171/FOC/2008/24/2/E8, indexed in Pubmed: 18275304.

2. Bhogesha S, Rimal D, Song C. The descending branch of lateral circumflex femoral artery (LCFA) as recipient pedicle for free flap cover of complex defects around the knee. Microsurgery. 2019; 39(6): 573-574, doi: 10.1002/micr.30459, indexed in Pubmed: 30968429.

3. Daksha Dixit DMK, Sureshbhai Rathod P, Mital Pateld M, et al. A study of variations in the origin of profunda femoris artery and its circumflex branches. Int J Biol Med Res. 2011; 2(4): 1084-1089.

4. Dan Z, Zhao L, Wang X. Applied anatomy of avascular necrosis of femoral head treated by interventional treatment of deep branch of medial circumflex femoral artery and ascending branch of lateral circumflex femoral artery. Sichuan J Anat. 2002; 2(02): 73-75.

5. Dewar DC, Lazaro LE, Klinger CE, et al. The relative contribution of the medial and lateral femoral circumflex arteries to the vascularity of the head and neck of the femur: a quantitative MRI-based assessment. Bone Joint J. 2016; 98-B(12): 1582-1588, doi: 10.1302/0301-620X.98B12.BJJ-2016-0251. R1, indexed in Pubmed: 27909118.

6. Fu W. The variation of profunda artery and its management in interventional intubation. J Int Radiol. 1999; 2: 61.

7. Hartog C, Metzler C, Meier C, et al. Anatomy of the lateral circumflex femoral artery: Does the direct anterior approach to the hip jeopardize vascularization of the proximal femur? Orthop Traumatol Surg Res. 2019; 105(7): 1257-1264, doi: 10.1016/j.otsr.2019.07.013, indexed in Pubmed: 31537495.

8. Hyun Kwon J, Hoon Shin Ji. Hypoplastic superficial femoral artery combined with connection of the deep femoral artery to the popliteal artery. Radiology Case Reports. 2018; 13(1): 39-42, doi: 10.1016/j.radcr.2017.10.028.

9. Jin W, Wei Z, Deng C, et al. Clinical application of free descending branch of lateral circumflex femoral artery perforator tissue flap and its impact on donor site. Zhongguo Xiu Fu Chong Jian Wai Ke Za Zhi. 2015; 29(10): 1284-1287, indexed in Pubmed: 26749740.

10. Kalhor M, Beck M, Huff TW, et al. Capsular and pericapsular contributions to acetabular and femoral head perfusion. J Bone Joint Surg Am. 2009; 91(2): 409-418, doi: 10.2106/ JBJS.G.01679, indexed in Pubmed: 19181985.

11. Łabętowicz $P$, Olewnik $Ł$, Podgórski $M$, et al. A morphological study of the medial and lateral femoral circumflex arteries: a proposed new classification. Folia Morphol. 2019; 78(4): 738-745, doi: 10.5603/FM.a2019.0033, indexed in Pubmed: 30906974.

12. Lee YC, Chen WC, Chou TM, et al. Anatomical variability of the anterolateral thigh flap perforators: vascular anatomy and its clinical implications. Plast Reconstr Surg. 2015; 135(4): 1097-1107, doi: 10.1097/PRS.0000000000001103, indexed in Pubmed: 25502859.

13. Liu $H$, Shao $D$, Guo J, et al. Applied anatomy of the profunda artery and its branches. Sichuan J Anat. 2001(03): 137-140.

14. Liu Y, Ding Q, Zang M, et al. Classification and application of the distally-based thigh flap based on the lateral circumflex femoral artery system. Ann Plast Surg. 2017; 78(5): 497-504, doi: 10.1097/SAP.0000000000000946, indexed in Pubmed: 28118225.
15. Luo XJ, Wang YT, Wang W, et al. Application of the descending branch of the lateral circumflex femoral artery in coronary artery bypass grafting. J Thorac Cardiovasc Surg. 2021; 161(4): 1266-1271, doi: 10.1016/j.jtcvs.2019.09.172, indexed in Pubmed: 31767359.

16. Nasr AY, Badawoud MH, Al-Hayani AA, et al. Origin of profunda femoris artery and its circumflex femoral branches: anatomical variations and clinical significance. Folia Morphol. 2014; 73(1): 58-67, doi: 10.5603/FM.2014.0008, indexed in Pubmed: 24590524.

17. Peng $\mathrm{C}$, Ge $\mathrm{S}$, Zhong $\mathrm{H}$, et al. case of left deep femoral artery with lateral circumflex femoral artery variation. Sichuan J Anat. 2015; 23(03): 62-63.

18. Prough $\mathrm{H}$, Alsayouri K. Anatomy, Bony Pelvis and Lower Limb, Lateral Circumflex Femoral Artery. StatPearls. StatPearls Publishing LLC, Treasure Island (FL) 2020.

19. Shang $Y, L i Y, N i n g Y$, et al. One case of lateral circumflex femoral artery variation. Progress of Anatomical Sciences. 2014; 20(03): 300.

20. Shen Yi, Lu LG, Low DW, et al. Perforator navigation using color Doppler ultrasound and three-dimensional reconstruction for preoperative planning of optimal lateral circumflex femoral artery system perforator flaps in head and neck reconstruction. J Plast Reconstr Aesthet Surg. 2019; 72(6): 990-999, doi: 10.1016/j.bjps.2018.12.025, indexed in Pubmed: 30880047.

21. Shi E, Fang G, Fu Y, et al. Applied anatomical investigation of femoral artery and its branches. J Baotou Med Coll. 2005; 04: 349-350.

22. Sinkeet SR, Ogeng'o JA, Elbusaidy H. Variant origin of the lateral circumflex femoral artery in a black Kenyan population. Folia Morphol. 2012; 71(1): 15-18, indexed in Pubmed: 22532179.

23. Sugawara $Y$, Sato $O$, Miyata T, et al. Utilization of the lateral circumflex femoral artery as a midway outflow for aorto-popliteal grafting: report of a case. Surg Today. 1998; 28(9): 967-970, doi: 10.1007/s005950050264, indexed in Pubmed: 9744412.

24. Tang X, Wei Z, Wang B, et al. Application of the lobulated flap or unilobular flap pedicled with the descending branch of lateral femoral circumflex artery in reconstruction of defects resulted from perineal and hypogastric tumor resection]. Zhonghua Zheng Xing Wai Ke Za Zhi. 2016; 32(2): 111-114, indexed in Pubmed: 30024686.

25. Tanyeli E, Uzel M, Yildirim M, et al. An anatomical study of the origins of the medial circumflex femoral artery in the Turkish population. Folia Morphol. 2006; 65(3): 209-212, indexed in Pubmed: 16988917.

26. Tomaszewski KA, Vikse J, Henry BM, et al. The variable origin of the lateral circumflex femoral artery: a meta-analysis and proposal for a new classification system. Folia Morphol. 2017; 76(2): 157-167, doi: 10.5603/FM.a2016.0056, indexed in Pubmed: 27714726.

27. Vazquez MT, Murillo J, Maranillo E, et al. Patterns of the circumflex femoral arteries revisited. Clin Anat. 2007; 20(2): 180-185, doi: 10.1002/ca.20336, indexed in Pubmed: 16617441.

28. Wang H, Li X, Li S, et al. Clinical application of anterolateral femoral flap with descending branch of circumflex lateral femoral artery and perforating branch of superior lateral genicular artery. Chin J Anat Clin. 2017; 22(6): 515-8, doi: 10.3760/cma.j.issn.2095-7041.2017.06.014. 